\title{
Erosive pustular dermatosis of the scalp
}

INSERM

\section{Source}

INSERM. (1999). Orphanet: an online rare disease and orphan drug data base. Erosive pustular dermatosis of the scalp. ORPHA:222

Erosive pustular dermatosis of the scalp is a rare chronic inflammation of the scalp usually occurring in elderly women ( $>70$ years old) and characterized by the development of painful pustules, shallow erosions, and crusting on atrophic skin that eventually result in cicatricial alopecia. 